\title{
Nursing Care after Hip Fracture Surgery Predicts Patient Ambulatory Ability at 3 Months after Surgery
}

\author{
Akiko Kondo ${ }^{1 *}$, Keiko Sada ${ }^{2}$, Chikae Yamaguchi ${ }^{3}$ and Etsuko Fujimoto ${ }^{4}$ \\ ${ }^{1}$ School of Nursing, Graduate School of Nursing, Tokyo Women's Medical University, Japan \\ ${ }^{2}$ Orthopedic Unit, Kasugai Municipal Hospital, Japan \\ ${ }^{3}$ School of Nursing, Nagoya City University, Japan \\ ${ }^{4}$ Department of Nursing, Nagoya University Graduate School of Medicine, Japan
}

\section{Abstract}

Purpose: This study examines whether nursing care predicts the incidence of complications, mortality, ambulatory ability at discharge and 3 months after surgery or the length of stay for patients who have undergone hip fracture surgery.

Methods: This is a retrospective observational study conducted at a community general hospital in Japan. Participants were patients who were 65 years or older and who had hip fracture surgery during the study period, April 2007 to March 2011. Data on demographics, treatments, nursing care and health outcomes during the hospital stay were collected from hospital records. A questionnaire regarding the patient's health outcomes after discharge was sent to patients and/or family members.

Results: In all, 449 patients met the inclusion criteria. The average age was 81.9 years, and $79.0 \%$ were female. In total, $94.4 \%$ of the patients were recorded as having obtained nursing care for getting out of bed, and $47.7 \%$ were recorded as having obtained nursing care for bearing weight. Nursing care associated with the topic "tell patients the necessity of getting out of bed early or encourage patients to get out of bed" were significantly related to a lower incidence of complication ( $\mathrm{OR}=0.341, \mathrm{P}=0.017)$. Patients with recorded nursing care for weight bearing had significantly greater ambulatory ability at discharge after adjusting for the introduction of the fixed-payment system, patient characteristics, type of surgery, hours of physical therapy and length of stay before surgery $(O R=1.890, P=0.006)$. Patients with recorded nursing care for weight bearing had significantly greater ambulatory ability at 3 months after adjusting for the same covariates $(\mathrm{OR}=2.175, \mathrm{P}=0.008)$.

Conclusion: Nursing care soon after surgery in an acute care hospital can improve the long-term outcomes of patients after they undergo hip fracture surgery. In addition to physical therapists, nurses should more willingly engage in the rehabilitation of patients in the orthopedic wards.

Keywords: Hip fracture; Nursing care; Get out of bed; Weight bearing; Pain control

\section{Introduction}

Hip fracture is one of the most common and potentially devastating injuries among elderly people and constitutes a socioeconomic problem in developed countries. The survival rate has significantly decreased by two years for patients after hip fracture compared to the general population without hip fracture, and the risk is even higher at ten years after hip fracture $[1,2]$.

Many developed countries have reduced the Length of Stay (LOS) to reduce medical costs. In the US, the Diagnostic Related Groups was introduced in 1983 for the purpose of limiting costs due to over-utilization of health services. Since the implementation of the prospective payment system, hospitals have reduced the amount of care given to patients with hip fractures and have shifted much of the rehabilitation burden to nursing homes, to the patients or to the families of patients. The increase in the number of patients remaining in nursing homes one year after hip surgery suggests that the overall quality of care may have deteriorated [3].

The Japanese government has also tried to reduce the LOS to save expenditures by instituting a kind of fixed payment plan called the Diagnosis Procedure Combination (DPC) [4] and by separating care provided in rehabilitation hospitals from that provided in acute care settings. This system is similar to the system in the US. The average LOS for general wards in Japan in 1999 was 27.2 days, which was decreased to 18.2 days in 2010 [5]. Reducing the LOS, however, may degrade hip fracture patients' outcomes at discharge as fewer patients are being discharged to their homes and fewer patients are able to walk independently at discharge [6]. Too short a LOS in acute care may even increase the mortality for hip fracture patients after discharge, as indicated by a comparison of the data for Japan and the US [7].

Therefore, nursing care that prevents decreasing patient outcomes is imperative. From a systematic review, multi-disciplinary rehabilitation after hip fracture surgery is associated with improved outcomes [8] in which nursing roles or nursing care are not specifically stated. Gregersen et al. [9] reported that multidisciplinary geriatric in-hospital intervention that included a nurse with geriatric expertise reduced LOS but did not affect patient outcome in terms of discharge destination, in-hospital mortality, or 3month mortality. A nurse with geriatric expertise in this article provided full-time geriatric care during daytime on weekdays. Olsson et al. [10] reported that an integrated care pathway, a multidisciplinary care plan that included nursing care, resulted in successful in-patient rehabilitation as measured at discharge. The care pathway was designed to focus on each patient's motivation and prerequisites for rehabilitation and guide the transition

*Corresponding author: Akiko Kondo, RN, PhD, School of Nursing, Graduate School of Nursing, Tokyo Women's Medical University, Tokyo, Japan, Tel: +81-33357-4804 (ext.6267); Fax: +81-20-4663-5779; E-mail: kondo.akiko@twmu.ac.jp

Received September 30, 2012; Accepted October 30, 2012; Published November 03, 2012

Citation: Kondo A, Sada K, Yamaguchi C, Fujimoto E (2012) Nursing Care after Hip Fracture Surgery Predicts Patient Ambulatory Ability at 3 Months after Surgery. J Nurs Care S5:002. doi:10.4172/2167-1168.S5-002

Copyright: $\odot 2012$ Kondo A, et al. This is an open-access article distributed under the terms of the Creative Commons Attribution License, which permits unrestricted use, distribution, and reproduction in any medium, provided the original author and source are credited. 
process. The intention is to create a pathway with rapid pre-operative attention and very early first ambulation. However, the effect of nursing care during hospitalization on patient outcome after discharge has not been reported in previous studies.

Early getting out of bed after surgery was associated with a decreased risk of mortality [7,11]. In addition, an early initial date of weight bearing after surgery predicts a higher ambulatory ability at 3 months after surgery [12]. This study examined 1) whether nursing care that encourages patients getting out of bed predicts incidence of complications or mortality, 2) whether nursing care that encourages patients to bear weight predicts ambulatory ability at discharge and 3 months after surgery, and 3) whether nursing care predicts LOS after surgery.

\section{Methodology}

This is a retrospective observational study in a community general hospital in the Tokai area of Japan (bed size approximately 500). The hospital introduced DPC in April, 2009. Data on demographics, treatments, and health outcomes during the hospital stay were collected from hospital records. A questionnaire was sent to patients and/or their family members regarding the patients' health outcomes after discharge from hip surgery.

\section{Selection of subjects}

Patients who were 65 years or older, who had experienced a hip fracture for the first time and who were admitted to the study hospital for surgery during the study period, April 2007 to March 2011, were selected for inclusion in the study. Exclusion criteria included patients who had been admitted to the hospital prior to their hip fracture, patients who could not walk with or without assistance before their hip fracture, patients who had fractures caused by metastatic cancer, or patients who had more than one fracture at the same time. Patients who were not medically allowed to get out of bed or bear weight during the hospitalization were also excluded.

\section{Human subjects}

Approvals were obtained from the Institutional Review Board of a university and the study hospital. A survey was mailed to participants with an informed consent form that included a brief description of the study and the survey, thus providing the participants with a clear understanding of how to complete and return the voluntary, confidential survey.

\section{Collection of data}

The hospital provided access to the inpatient/outpatient medical records of patients who had hip fracture surgery during the study period. During the medical records review, patients were selected according to the abovementioned inclusion and exclusion criteria.

A letter was sent from a co-investigator of the hospital to the study patients who met the study inclusion criteria. The informed consent and surveys were sent to the billing addresses used during the patients' last hospitalizations. Patients and/or their family members were asked to sign the consent form and to complete and return the questionnaire in a self-addressed stamped envelope within two weeks if they agreed to participate in the study. The questionnaire asked for an assessment of the patients' ambulatory ability at 3 months after surgery and of their current ambulatory ability and the date and cause of death for those who died.

Variables collected from medical records included the patients' demographics, treatments, nursing care and outcomes during hospitalization. Patients' demographics included age, gender, comorbidities, ambulatory ability before fracture, and location of residence before fracture. Data regarding treatment included the dates of admission and discharge, dates and type of surgery, the postoperative day that getting out of bed and weight bearing were allowed by the surgeon in charge, the postoperative day that the patient actually first got out of bed, the postoperative day that the patient actually first bore weight, the pain level at the time of initial getting out of bed and initial weight bearing and the total hours of physical therapy during hospitalization. Variables regarding nursing care included encouraging patients to get out of bed and bear weight, Outcomes during hospitalization included complication after surgery, the ambulatory ability at discharge, and the discharge location. Mortality data were obtained from the survey (family member) or hospital records for patients who had died in the hospital. Ambulatory ability at 3 months after surgery was collected from outpatient records for those patients who did not return the survey.

\section{Measurements}

Patients who were admitted before April $1^{\text {st }} 2009$ were categorized as pre-DPC introduction, while those who were admitted on or after April $1^{\text {st }}$ in 2009 were categorized as post-DPC. The LOS was calculated as the date of discharge minus the date of admission at the study hospital. The LOS included the days when patients stayed in the orthopedic acute care unit or other acute care units for the treatment of comorbidities or complications. The LOS after surgery was calculated as the date of discharge minus the date of surgery. 'Follow-up days' was defined as the date that the patient died or when follow-up was censored minus the date of surgery. Follow-up was censored at the time of investigation, the day of the last outpatient visit or the day of discharge from the hospital. Ambulatory ability was determined from the medical records and the questionnaire using a 6 -level scale ( $1=$ walk independently without use of equipment, $2=$ walk with a cane, $3=$ walk with a walking frame or cart, $4=$ walk with people's assistance, $5=$ use wheel chair, $6=$ confined to bed).

Comorbidities were defined as the conditions that patients had before surgery. Each comorbidity was collected using a 3-level scale ( $0=$ never had, $1=$ used to have but currently does not have, and $2=$ currently has). Comorbidities included anemia, arrhythmia, audio disorder, asthma, cancer, cerebrovascular disease, cholelithiasis, heart failure, liver disease, chronic obstructive pulmonary disease, dementia, depression, diabetes mellitus, epilepsy, gastrointestinal disorder, hematologic disorder, hypercholesterolemia/lipidemia, hypertension, ischemic heart disease, mental disorder, myocardial infarction, osteoarthritis, osteoporosis, paralysis, Parkinson's disease, pneumonia, renal failure, rheumatoid arthritis, thyroid disease, urinary incontinence, valvular heart disease, vertebral disorder, tuberculosis, visual disorder, fracture of leg or vertebra, and others. Complications were defined as conditions that occurred during or after hip fracture surgery. Complications included anemia, urinary tract infection, delirium/dementia, deep vein thrombosis, respiratory disorders, cardiovascular disorders, neurologic disorders, infection or necrosis of surgery site, and others. Pain level was measured on a 5 -level scale ( $1=$ minimum pain $\sim 5=$ cannot stand).

\section{Statistical Analysis}

The PASW version 18.0 for Windows was used for analyses. Variables were statistically compared between patients for whom nursing care for getting out of bed was recorded and those for whom nursing care was not recorded as well as between patients for whom nursing care for weight bearing was recorded and for those for whom it was not recorded. Pearson's chi-square tests or Fisher's exact tests were 
used to compare the categories/ratios of variables, such as gender, type of surgery, place of residence, and survival rate. Continuous variables, such as age and LOS, were compared using $t$-tests, if the variance was homogeneous; otherwise, Mann-Whitney U tests were used. Ordinal measures, such as comorbidities, complications, and ambulatory ability, were compared using Mann-Whitney U tests.

If a patient had at least one complication, the patient was regarded as having had an incidence of complication, and multiple logistic regression was used to test the relationship between nursing care and the incidence of any complication. The relationship between nursing care for getting out of bed and mortality was tested using Cox proportional hazards model. The ambulatory ability at discharge and at 3 months was separated into 2 categories, "able to walk independently with or without equipment" (1 3 on a 6-level scale) or not. The relationship between nursing care for weight bearing and ambulatory ability at discharge and at 3 months after surgery was tested using the multiple logistic regressions. Whether the pain level at the initial weight bearing predicts ambulatory ability at discharge and at 3 months after surgery was also analyzed. The outcome variable of LOS after surgery was separated into 2 categories with the median day as "shorter than 20 days" or " 21 days and longer". The relationship between nursing care and LOS after surgery was also tested using multiple logistic regressions. Patients who died during hospitalization were excluded from the analysis of the relationship between nursing care and LOS after surgery.

The following were selected as covariates: factors with empirical support or a theoretical basis of being related to mortality, ambulatory ability or LOS after surgery, such as patients' characteristics of age, gender, residence before fracture, ambulatory ability before fracture, comorbidities and complications; and process of care such as LOS before surgery, type of surgery and total hours of physical therapy. The variable DPC introduction was also included in the multivariate analyses. The type of surgery was categorized as compression hip screw or hip replacement. An alpha level of less than 0.05 was considered as statistically significant.

\section{Results}

For this study, 499 patients met the inclusion criteria. The average age of the participants was 81.9 years $(\mathrm{SD}=8.1)$, and $79.0 \%(\mathrm{n}=354)$ were female. A total of $94.4 \%(n=423)$ of patients were recorded as having obtained nursing care for getting out of bed, and $47.7 \%(n=214)$ were recorded as having obtained nursing care for weight bearing. Four patients $(0.9 \%)$ died during hospitalization. The survey was returned from $290(64.6 \%)$ patients/families, and ambulatory ability at 3 months after surgery was available for 313 (69.7\%) patients either from outpatient records or from the survey. The average number of observation days was $505.4(\mathrm{SD}=359.6)$ days after surgery.

Table 1 shows the types of nursing care related to getting out of beds. The main categories were "tell patients the necessity of getting out

Table 1: Nursing cares for getting out of bed.

\begin{tabular}{|l|c|}
\hline Nursing cares for getting out of bed & $\mathrm{n}(\%)$ \\
\hline Tell patients the necessity of getting out of bed early & $111(26.2)$ \\
\hline Pain control & $32(7.5)$ \\
\hline Others (mainly transfer assistance) & $217(51.2)$ \\
\hline Tell patients necessity of getting out of bed early and pain control & $51(12.0)$ \\
\hline Pain control and others & $8(1.9)$ \\
\hline Tell patients necessity of getting out of bed early and others & $4(0.9)$ \\
\hline All of above & $1(0.2)$ \\
\hline Total & $424(100.0)$ \\
\hline
\end{tabular}

Table 2: Comparison of patients who were recorded nursing care for getting out of bed and who were not.

\begin{tabular}{|c|c|c|c|c|c|}
\hline \multirow[t]{2}{*}{$N=449$} & \multicolumn{2}{|c|}{$\begin{array}{l}\text { Patients recorded } \\
\text { nursing care for } \\
\text { getting out of bed }\end{array}$} & \multicolumn{2}{|c|}{$\begin{array}{c}\text { Patients with no } \\
\text { record of nursing } \\
\text { care for getting } \\
\text { out of bed }\end{array}$} & \multirow[t]{2}{*}{$P$} \\
\hline & $\mathrm{n}$ & & $\mathrm{n}$ & & \\
\hline Average age (SD) & 424 & $81.8(8.1)$ & 25 & $82.0(8.5)$ & $0.907^{*}$ \\
\hline Female, n(\%) & 423 & $340(80.4)$ & 25 & $14(56.0)$ & $0.009 *$ \\
\hline $\begin{array}{l}\text { Lived home before fracture, } \\
\mathrm{n}(\%)\end{array}$ & 424 & $364(85.8)$ & 25 & $21(84.0)$ & $0.769 *$ \\
\hline Comorbidity score, mean rank & 424 & 226 & 25 & 204 & $0.410 \S$ \\
\hline $\begin{array}{l}\text { Able to walk without equipment } \\
\text { before fracture }\end{array}$ & 423 & $279(66.0)$ & 25 & $13(52.0)$ & $0.194 \%$ \\
\hline $\begin{array}{l}\text { Transcervical type of fracture, } \\
n(\%)\end{array}$ & 421 & 185 (43.9) & 24 & $11(45.8)$ & $0.856 \#$ \\
\hline $\begin{array}{l}\text { Compression hip screw } \\
\text { surgery, } n(\%)\end{array}$ & 424 & $313(73.8)$ & 25 & $19(76.0)$ & $1.000 \%$ \\
\hline $\begin{array}{l}\text { Initial date of getting out of bed } \\
\text { after surgery, mean (median) }\end{array}$ & 424 & $1.7(1.0)$ & 25 & $2.3(2.0)$ & $0.068^{*}$ \\
\hline $\begin{array}{l}\text { Pain level at the initial getting } \\
\text { out of bed (mean rank) }\end{array}$ & 356 & 196 & 23 & 104 & $<0.001 \S$ \\
\hline $\begin{array}{l}\text { Difference between permission } \\
\text { date and actual date of getting } \\
\text { out of bed, mean (median) }\end{array}$ & 424 & $0.5(0.0)$ & 25 & $0.9(0.0)$ & $0.067 \S$ \\
\hline $\begin{array}{l}\text { Initial date of weight bearing, } \\
\text { mean (median) }\end{array}$ & 411 & $2.7(1.0)$ & 25 & $2.9(2.0)$ & $0.072^{*}$ \\
\hline $\begin{array}{l}\text { Incidence of any complication, } \\
\mathrm{n}(\%)\end{array}$ & 424 & $75(17.7)$ & 25 & $6(24.0)$ & $0.424 *$ \\
\hline Length of stay, mean (median) & 424 & $28.5(24.5)$ & 25 & $26.7(8.4)$ & $0.737^{*}$ \\
\hline $\begin{array}{l}\text { Length of stay after surgery, } \\
\text { mean (median) }\end{array}$ & 424 & $23.4(19.5)$ & 25 & $21.9(21.0)$ & $0.783^{*}$ \\
\hline $\begin{array}{l}\text { Able to walk independently } \\
\text { with or without equipment at } \\
\text { discharge, } n(\%)\end{array}$ & 420 & $238(56.7)$ & 25 & $11(44.0)$ & $0.215 \#$ \\
\hline Inpatient mortality, n(\%) & 424 & $4(0.9)$ & 25 & $0(0.0)$ & $1.000 *$ \\
\hline Discharged to home, $\mathrm{n}(\%)$ & 420 & $92(21.9)$ & 25 & $5(20.0)$ & $1.000 *$ \\
\hline Mortality, n(\%) & 424 & $51(12.0)$ & 25 & $4(16.0)$ & $0.556 \#$ \\
\hline $\begin{array}{l}\text { Observation days, mean } \\
\text { (median) }\end{array}$ & 424 & $\begin{array}{c}508.7 \\
(467.0)\end{array}$ & 25 & $\begin{array}{c}449.8 \\
(358.0)\end{array}$ & $0.427^{*}$ \\
\hline
\end{tabular}

*t-test, \#chi-square test, ※Fisher's exact test, §Mann-Whitney U test

of bed early or encourage patients to get out of bed" and "pain control." Only $12 \%$ of the patients were recorded with as having received both forms of care. "Pain control" was regarded as applied if pain medication was administered before the patient got out of bed. The category "Others" mainly included transfer assistance. Table 2 compares patients' characteristics, their process of care and the outcomes between those for whom nursing care for getting out of bed were recorded and those for whom it was not. There were no significant differences in patients' basic characteristics other than gender. There were no significant differences in the initial date of getting out of bed and other processes of care, incidence of complication, LOS or mortality. The pain level at the initial getting out of bed was significantly higher in patients for whom nursing care for getting out of bed was recorded. There was no significant difference in the difference between the permission date and actual date of getting out of bed. Approximately $20 \%$ of the patients were discharged to their home or their family's home, while the others were discharged to a rehabilitation hospital or another hospital (Table 2).

The main complications included anemia (7.8\%), delirium/ dementia $(2.9 \%)$, cardiovascular disorder $(2.2 \%)$, digestive disorder (2.0\%), respiratory disorder $(1.3 \%)$, fall $(1.1 \%)$, decubitus $(0.9 \%)$, urinary infection $(0.7 \%)$, deep vein thrombosis $(0.4 \%)$, cerebral 
vascular disorder $(0.4 \%)$ and problems at the surgery site $(0.4 \%)$. Table 3 shows the factors related to the incidence of at least one complication. Nursing care associated with "tell patients the necessity of getting out of bed early or encourage the patient to get out of bed" was significantly related to a lower incidence of complications (Odds Ratio $(\mathrm{OR})=0.341$, $\mathrm{P}=0.017)$. Table 4 shows the factors that independently predicted mortality in the Cox regression. No type of nursing care for getting out of bed was significantly related to lower mortality, while the incidence of complications significantly predicted higher mortality (Hazard Risk=2.561, $\mathrm{P}=0.004)$.

Table 5 shows the kinds of nursing care for weight bearing. The main cares were "tell patients the necessity of weight bearing or encourage patient to bear weight" and "pain control. Approximately $21 \%$ of the patients were recorded as having received both types of care. The category "Others" mainly included transfer or walking assistance to the bathroom. Table 6 compares the patients' characteristics, process of care and outcomes between those for whom nursing care for weight bearing was recorded and those for whom it was not. There were no significant differences in the patients' basic characteristics or type of surgery. The initial date of weight bearing was significantly earlier for patients for whom nursing care for weight bearing was recorded $(\mathrm{P}=0.015)$, and the incidence of complications was significantly higher in patients without recorded nursing care for weight bearing $(\mathrm{P}=0.001)$. There were no

Table 3: Factors predict incidence of complication.

\begin{tabular}{|l|c|c|c|}
\hline Independent variables & $\mathrm{B}$ & Odds Ratio $(95 \% \mathrm{Cl})$ & $\mathrm{P}$ \\
\hline $\begin{array}{l}\text { Introduction of Diagnosis Procedure } \\
\text { Combination }\end{array}$ & 0.419 & $1.512(0.895-2.583)$ & 0.121 \\
\hline Age & 0.048 & $1.049(1.013-1.086)$ & 0.008 \\
\hline Female gender & -0.777 & $0.460(0.247-0.857)$ & 0.014 \\
\hline Lived home before fracture & -0.284 & $0.753(0.378-1.499)$ & 0.419 \\
\hline Ambulatory ability before fracture & -0.103 & $0.902(0.667-1.221)$ & 0.506 \\
\hline Number of comorbidities & 0.020 & $1.020(0.937-1.111)$ & 0.650 \\
\hline Length of stay before surgery & 0.024 & $1.025(0.950-1.105)$ & 0.526 \\
\hline Compression hip screw surgery & -0.119 & $0.888(0.484-1.627)$ & 0.701 \\
\hline $\begin{array}{l}\text { Tell patients the necessity of getting out of } \\
\text { bed early }\end{array}$ & -1.074 & $0.341(0.141-0.825)$ & 0.017 \\
\hline Pain control & 0.264 & $1.302(0.592-2.866)$ & 0.511 \\
\hline Others (mainly transfer assist) & 0.444 & $1.559(0.691-3.517)$ & 0.285 \\
\hline
\end{tabular}

Logistic regression

Dependent variable: "incidence of at least one complication" $=1$, "no complication" $=0$ Nagelkerke $\mathrm{R}^{2}=0.141$

Hosmer \& Lemeshow test: $x 2=5.646, d f=8, P=0.687$

Table 4: Factors predict mortality.

\begin{tabular}{|l|c|c|c|}
\hline Independent variables & $\mathrm{B}$ & Hazard Risk (95\%Cl) & $\mathrm{P}$ \\
\hline $\begin{array}{l}\text { Introduction of Diagnosis Procedure } \\
\text { Combination }\end{array}$ & -0.035 & $0.966(0.510-1.830)$ & 0.915 \\
\hline Age & 0.051 & $1.052(1.012-1.095)$ & 0.011 \\
\hline Female gender & -0.563 & $0.569(0.289-1.123)$ & 0.104 \\
\hline Lived home before fracture & -0.020 & $0.980(0.500-1.922)$ & 0.954 \\
\hline Ambulatory ability before fracture & 0.440 & $1.553(1.184-2.037)$ & 0.001 \\
\hline Number of comorbidities & 0.059 & $1.061(0.983-1.144)$ & 0.128 \\
\hline Length of stay before surgery & -0.002 & $0.998(0.917-1.088)$ & 0.970 \\
\hline Compression hip screw surgery & -0.192 & $0.826(0.426-1.600)$ & 0.570 \\
\hline Incidence of complication & 0.940 & $2.561(1.340-4.893)$ & 0.004 \\
\hline $\begin{array}{l}\text { Tell patients the necessity of getting out of } \\
\text { bed early }\end{array}$ & 0.258 & $1.294(0.550-3.042)$ & 0.555 \\
\hline Pain control & 0.309 & $1.362(0.659-2.813)$ & 0.404 \\
\hline Others (mainly transfer assist) & -0.207 & $0.813(0.331-1.998)$ & 0.652 \\
\hline
\end{tabular}

Cox regression

Observation period is days after surgery.
Table 5: Nursing care for weight bearing

\begin{tabular}{|l|c|}
\hline Nursing care for weight bearing & $\mathrm{n}(\%)$ \\
\hline Tell patients the necessity of weight bearing & $90(42.1)$ \\
\hline Pain control & $35(16.4)$ \\
\hline Others (mainly transfer or walking assistance to the bathroom) & $41(19.2)$ \\
\hline Tell patients the necessity of weight bearing and pain control & $45(21.0)$ \\
\hline Tell patients the necessity of weight bearing and others & $2(0.9)$ \\
\hline Pain control and others & $1(0.5)$ \\
\hline Total & $214(100.0)$ \\
\hline
\end{tabular}

Table 6: Comparison of patients who were recorded nursing care for weight bearing and who were not.

\begin{tabular}{|c|c|c|c|c|c|}
\hline \multirow[t]{2}{*}{$N=449$} & \multicolumn{2}{|c|}{\begin{tabular}{|c|} 
Recorded \\
nursing care for \\
weight bearing
\end{tabular}} & \multicolumn{2}{|c|}{$\begin{array}{l}\text { No record of } \\
\text { nursing care for } \\
\text { weight bearing }\end{array}$} & \multirow[t]{2}{*}{$P$} \\
\hline & $\mathrm{n}$ & & $\mathrm{n}$ & & \\
\hline Average age (SD) & 214 & $81.5(8.1)$ & 235 & $82.2(8.1)$ & $0.340^{*}$ \\
\hline Female, n(\%) & 214 & $177(82.7)$ & 234 & $177(75.6)$ & $0.066 \#$ \\
\hline Lived home before fracture, $\mathrm{n}(\%)$ & 214 & $190(88.8)$ & 235 & $195(83.0)$ & $0.079 \#$ \\
\hline Comorbidity score, mean rank & 214 & 212 & 235 & 237 & $0.870 \S$ \\
\hline $\begin{array}{l}\text { Able to walk without equipment } \\
\text { before fracture }\end{array}$ & 214 & $143(66.8)$ & 234 & $149(63.7)$ & $0.485 \#$ \\
\hline Transcervical type of fracture, $n(\%)$ & 213 & $117(54.9)$ & 232 & $132(56.9)$ & $0.676 \#$ \\
\hline $\begin{array}{l}\text { Compression hip screw surgery, } \\
\mathrm{n}(\%)\end{array}$ & 214 & $157(73.4)$ & 235 & $175(74.5)$ & $0.790 \#$ \\
\hline $\begin{array}{l}\text { Initial date of getting out of bed after } \\
\text { surgery, mean (median) }\end{array}$ & 214 & $1.8(1.8)$ & 235 & $1.6(1.4)$ & $0.362 \S$ \\
\hline $\begin{array}{l}\text { Initial date of weight bearing, mean } \\
\text { (median) }\end{array}$ & 213 & $2.3(1.0)$ & 223 & $3.1(1.0)$ & $0.015 \S$ \\
\hline $\begin{array}{l}\text { Pain level at the initial date of weight } \\
\text { bearing (mean rank) }\end{array}$ & 175 & 187 & 192 & 182 & $0.635 \S$ \\
\hline $\begin{array}{l}\text { Difference between permission } \\
\text { date and actual date of initial weight } \\
\text { bearing, mean (median) }\end{array}$ & 213 & $0.8(0.0)$ & 223 & $1.0(0.0)$ & $0.304^{*}$ \\
\hline Incidence of any complication, $\mathrm{n}(\%)$ & 214 & $25(11.7)$ & 235 & $56(23.8)$ & $0.001 \#$ \\
\hline $\begin{array}{l}\text { Hours of physical therapy, mean } \\
\text { (median) }\end{array}$ & 214 & $7.7(6.0)$ & 235 & $6.6(6.6)$ & $0.208^{*}$ \\
\hline Length of stay, mean (median) & 214 & $29.3(21.0)$ & 235 & $\begin{array}{c}27.6 \\
(25.0)\end{array}$ & $0.502^{*}$ \\
\hline $\begin{array}{l}\text { Length of stay after surgery, mean } \\
\text { (median) }\end{array}$ & 214 & $24.3(19.0)$ & 235 & $\begin{array}{c}22.4 \\
(20.0)\end{array}$ & $0.463^{*}$ \\
\hline Discharge to home, $\mathrm{n}(\%)$ & 211 & $49(23.2)$ & 234 & $48(20.5)$ & $0.489 \#$ \\
\hline $\begin{array}{l}\text { Able to walk independently with or } \\
\text { without equipment at discharge, } \\
n(\%)\end{array}$ & 211 & $136(64.5)$ & 234 & $113(48.3)$ & $0.001 \#$ \\
\hline $\begin{array}{l}\text { Able to walk independently with or } \\
\text { without equipment at } 3 \text { month, } n(\%)\end{array}$ & 145 & $111(76.6)$ & 168 & $102(60.7)$ & $0.003 \#$ \\
\hline $\begin{array}{l}\text { Able to walk independently with or } \\
\text { without equipment at the time of } \\
\text { investigation } n(\%)\end{array}$ & 108 & $79(73.1)$ & 127 & $77(60.6)$ & $0.043 \#$ \\
\hline Mortality, n(\%) & 214 & $26(12.1)$ & 235 & $29(12.3)$ & $0.951 \#$ \\
\hline
\end{tabular}

*t-test, \#chi-square test, §Mann-Whitney $U$ test

significant differences in the total hours of physical therapy, LOS or discharge location. The ambulatory ability at discharge $(\mathrm{P}=0.001)$, at 3 months after surgery $(\mathrm{P}=0.003)$, and at the time of investigation $(\mathrm{P}=0.043)$ was significantly higher in patients with recorded nursing care for weight bearing.

Table 7 shows factors related to independent walking at discharge. Patients with recorded nursing care for weight bearing had a significantly higher ambulatory ability at discharge after adjusting for DPC introduction, patient characteristics, type of surgery, hours of physical therapy and LOS before surgery $(\mathrm{OR}=1.890, \mathrm{P}=0.006)$. 
Table 7: Factors related to independent walking at discharge.

\begin{tabular}{|l|c|l|c|}
\hline Independent variables & $\mathrm{B}$ & Odds Ratio $(95 \% \mathrm{Cl})$ & $\mathrm{P}$ \\
\hline Introduction of Diagnosis Procedure Combination & -0.585 & $0.557(0.354-0.878)$ & 0.012 \\
\hline Age & -0.056 & $0.946(0.917-0.975)$ & $<0.001$ \\
\hline Female gender & 0.499 & $1.647(0.927-2.927)$ & 0.089 \\
\hline Lived home before fracture & 0.683 & $1.979(0.996-3.931)$ & 0.051 \\
\hline Ambulatory ability before fracture & -0.853 & $0.426(0.323-0.563)$ & $<0.001$ \\
\hline Number of comorbidities & -0.090 & $0.914(0.853-0.980)$ & 0.011 \\
\hline Compression hip screw surgery & -0.209 & $0.812(0.463-1.422)$ & 0.466 \\
\hline Incidence of complication & -0.801 & $0.449(0.247-0.816)$ & 0.009 \\
\hline Hours of physical therapy & 0.086 & $1.090(1.017-1.169)$ & 0.015 \\
\hline Length of stay before surgery & -0.061 & $0.941(0.876-1.010)$ & 0.092 \\
\hline Nursing care for weight bearing & 0.636 & $1.890(1.199-2.977)$ & 0.006 \\
\hline
\end{tabular}

Logistic regression

Dependent variable: "able to walk independently with or without equipment at discharge" $=1$,

"not able to walk independently with or without equipment at discharge" $=0$

Nagelkerke $R^{2}=0.366$

Hosmer \& Lemeshow test: $\mathrm{x} 2=6143, \mathrm{df}=8, \mathrm{P}=0.631$

Table 8: Nursing cares related to independent walking at discharge.

\begin{tabular}{|l|c|c|c|}
\hline Independent variables & $\mathrm{B}$ & Odds Ratio $(95 \% \mathrm{Cl})$ & $\mathrm{P}$ \\
\hline Introduction of Diagnosis Procedure Combination & -0.528 & $0.590(0.370-0.939)$ & 0.026 \\
\hline Age & -0.056 & $0.945(0.917-0.975)$ & $<0.001$ \\
\hline Female gender & 0.488 & $1.630(0.914-2.905)$ & 0.098 \\
\hline Lived home before fracture & 0.682 & $1.978(0.996-3.932)$ & 0.052 \\
\hline Ambulatory ability before fracture & -0.880 & $0.415(0.313-0.550)$ & $<0.001$ \\
\hline Number of comorbidities & -0.092 & $0.912(0.850-0.979)$ & 0.010 \\
\hline Compression hip screw surgery & -0.208 & $0.812(0.457-1.445)$ & 0.480 \\
\hline Incidence of complication & -0.773 & $0.461(0.251-0.848)$ & 0.013 \\
\hline Hours of physical therapy & 0.087 & $1.090(1.016-1.170)$ & 0.016 \\
\hline Length of stay before surgery & -0.064 & $0.938(0.873-1.008)$ & 0.081 \\
\hline $\begin{array}{l}\text { Tell patients of the necessity of weight } \\
\text { bearing }\end{array}$ & 0.713 & $2.040(1.183-3.519)$ & 0.010 \\
\hline Pain control & 0.180 & $1.197(0.638-2.245)$ & 0.575 \\
\hline Others (mainly transfer/walk assist) & 0.825 & $2.281(0.990-5.256)$ & 0.053 \\
\hline
\end{tabular}

\section{Logistic regression}

Dependent variable: "able to walk independently with or without equipment at discharge" $=1$,

"not able to walk independently with or without equipment at discharge" $=0$

Nagelkerke $\mathrm{R}^{2}=0.372$

Hosmer \& Lemeshow test: $\mathrm{X} 2=5.809, \mathrm{df}=8, \mathrm{P}=0.669$

The patient ambulatory ability significantly decreased at post-DPC introduction $(\mathrm{OR}=0.557, \mathrm{P}=0.012)$. Table 8 shows specific nursing care for weight bearing related to independent walking at discharge. The factors "tell patients of the necessity of weight bearing or encourage the patient to bear weight" $(\mathrm{OR}=2.040, \mathrm{P}=0.010)$ significantly predicted independent walking at discharge. Table 9 indicated that a higher pain level at initial weight bearing significantly predicted a lower ambulatory ability at discharge $(\mathrm{OR}=0.743, \mathrm{P}=0.014)$.

Table 10 shows factors related to independent walking at 3 months after surgery. Patients with recorded nursing care for weight bearing demonstrated significantly higher ambulatory ability at 3 months after adjusting for DPC introduction, patients' basic characteristics, type of surgery, incidence of complication, hours of rehabilitation and LOS before surgery $(\mathrm{OR}=2.175, \mathrm{P}=0.008)$. The hours of physical therapy did not predict the ambulatory ability at 3 months.

No specific nursing care for weight bearing independently predicted the ambulatory ability at 3 months. The pain level at initial weight bearing was not related to ambulatory ability at 3 months after surgery.
Table 11 shows factors related to LOS after surgery. None of the nursing care significantly predicted LOS after surgery. Introduction of DPC $(\mathrm{OR}=2.321, \mathrm{P}<0.001)$, lower ambulatory ability before fracture $(\mathrm{OR}=1.272, \mathrm{P}=0.041)$ and incidence of complications

Table 9: Relationship between pain level at initial weight bearing and ambulatory ability at discharge.

\begin{tabular}{|l|c|c|c|}
\hline Independent variables & $\mathrm{B}$ & Odds Ratio $(95 \% \mathrm{CI})$ & $\mathrm{P}$ \\
\hline Introduction of Diagnosis Procedure Combination & -0.647 & $0.524(0.310-0.884)$ & 0.016 \\
\hline Age & -0.059 & $0.943(0.910-0.976)$ & $<0.001$ \\
\hline Female gender & 0.729 & $2.072(1.079-3.982)$ & 0.029 \\
\hline Lived home before fracture & 0.889 & $2.432(1.075-5.503)$ & 0.033 \\
\hline Ambulatory ability before fracture & -0.915 & $0.401(0.293-0.547)$ & $<0.001$ \\
\hline Number of comorbidities & -0.094 & $0.910(0.838-0.989)$ & 0.026 \\
\hline Compression hip screw surgery & -0.330 & $0.719(0.383-1.351)$ & 0.305 \\
\hline Incidence of complication & -0.915 & $0.401(0.206-0.781)$ & 0.007 \\
\hline Hours of physical therapy & 0.062 & $1.064(0.983-1.151)$ & 0.125 \\
\hline Length of stay before surgery & -0.031 & $0.970(0.894-1.051)$ & 0.454 \\
\hline Pain level at the initial weight bearing & -0.297 & $0.743(0.586-0.942)$ & 0.014 \\
\hline
\end{tabular}

Logistic regression

Dependent variable: "able to walk independently with or without equipment at discharge" $=1$

"not able to walk independently with or without equipment at discharge" $=0$ Nagelkerke $\mathrm{R}^{2}=0.377$

Hosmer \& Lemeshow test: $\mathrm{X} 2=12.27, \mathrm{df}=8, \mathrm{P}=0.139$

Table 10: Factors related to independent walking at 3 months after surgery. \begin{tabular}{|l|c|l|c|}
\hline Independent variables & B & Odds Ratio $(95 \% \mathrm{Cl})$ & $\mathrm{P}$
\end{tabular} \begin{tabular}{|l|l|l|l|l|}
\hline Introduction of Diagnosis Procedure Combination & -0.515 & $0.598(0.338-1.056)$ & 0.076
\end{tabular} Age

Female gender

Lived home before fracture

Ambulatory ability before fracture

Number of comorbidities

Compression hip screw surgery

Incidence of complication

Hours of physical therapy

Length of stay before surgery

Recorded nursing care for weight bearing $-0.0760 .927(0.891-0.964)<0.001$ \begin{tabular}{|l|l|l|l|}
\hline-0.016 & $0.984(0.455-2.126)$ & 0.967 \\
\hline
\end{tabular} \begin{tabular}{|l|l|l|l|}
\hline 1.002 & $2.725(1.222-6.077)$ & 0.014 \\
\hline
\end{tabular} $-0.6510 .521(0.381-0.713)<0.001$ \begin{tabular}{l|l|l|l|}
-0.064 & $0.938(0.860-1.023)$ & 0.148 \\
\hline
\end{tabular} \begin{tabular}{|l|l|l|}
\hline 0.435 & $1.545(0.766-3.119)$ & 0.225 \\
\hline
\end{tabular} $-0.5860 .557(0.271-1.142) \quad 0.110$ \begin{tabular}{|l|l|l|}
\hline 0.007 & $1.007(0.959-1.056)$ & 0.791 \\
\hline
\end{tabular} \begin{tabular}{|c|c|c|}
-0.017 & $0.983(0.900-1.074)$ & 0.710 \\
\hline
\end{tabular} \begin{tabular}{|l|l|l|}
0.777 & $2.175(1.219-3.880)$ & 0.008 \\
\hline
\end{tabular}

Logistic regression

Dependent variable: "able to walk independently with or without equipment at 3 months"=1,

"not able to walk independently with or without equipment at 3 months" $=0$ Nagelkerke $\mathrm{R}^{2}=0.342$

Hosmer \& Lemeshow test: $\mathrm{X} 2=12.50, \mathrm{df}=8, \mathrm{P}=0.130$

Table 11: Factors related to longer length of stay after surgery.

\begin{tabular}{|l|c|c|c|}
\hline Independent variables & $\mathrm{B}$ & Odds Ratio $(95 \% \mathrm{Cl})$ & $\mathrm{P}$ \\
\hline Introduction of Diagnosis Procedure Combination & 0.842 & $2.321(1.557-3.459)$ & $<0.001$ \\
\hline Age & 0.010 & $1.010(0.983-1.037)$ & 0.474 \\
\hline Female gender & 0.278 & $1.321(0.784-2.225)$ & 0.296 \\
\hline Lived home before fracture & 0.418 & $1.518(0.842-2.739)$ & 0.165 \\
\hline Ambulatory ability before fracture & 0.240 & $1.272(1.010-1.601)$ & 0.041 \\
\hline Number of comorbidities & 0.025 & $1.025(0.964-1.090)$ & 0.431 \\
\hline Length of stay before surgery & 0.007 & $1.007(0.947-1.072)$ & 0.816 \\
\hline Compression hip screw surgery & -0.344 & $0.709(0.435-1.154)$ & 0.166 \\
\hline Incidence of complication & 0.787 & $2.196(1.279-3.770)$ & 0.004 \\
\hline Recorded nursing care for getting out of bed & -0.137 & $0.872(0.365-2.083)$ & 0.757 \\
\hline Recorded nursing care for weight bearing & -0.060 & $0.942(0.626-1.416)$ & 0.773 \\
\hline
\end{tabular}

Logistic regression

Depemdent variable: length of stay after surgery $\leqq 20$ days $=0,20$ days and longer $=1$

Nagelkerke $R^{2}=0.117$

Hosmer \& Lemeshow test: $X 2=11.19, d f=8, P=0.191$ 
$(\mathrm{OR}=2.196, \mathrm{P}=0.004)$ significantly predicted a longer LOS after surgery.

\section{Discussion}

This study analyzed whether nursing care after surgery during hospitalization predicts patient outcome at discharge and after discharge. Nursing care for getting out of bed was significantly related to a lower incidence of complications, although it did not predict LOS after surgery or mortality. Nursing care for weight bearing significantly predicted a higher ambulatory ability not only at discharge but also at 3 months after surgery. When nursing care included encouraging patients to bear weight, patients were twice as likely to walk independently at discharge and at 3 months.

It is difficult to determine in this study whether nursing care for getting out of bed reduced the incidence of complications or if nursing care for getting out of bed was not used for patients with complications because of bad general condition. However, this study was limited to patients who were eventually allowed to get out of bed even though they had complications. Getting out of bed accelerates blood circulation and respiratory functions, which contribute to preventing complications or to recovering from complications. The timing for getting out of bed was later in Japanese hospitals than in US hospitals, although the incidence of complications was lower compared to US hospitals ( 2.5 days vs. 1.6 days after surgery) [7]. In this study, the timing for getting out of bed was earlier than that in the Japanese hospitals in the previous study, but it was still later when compared to that in the US hospitals. Nursing care for getting out of bed is necessary, even for patients who were delayed in getting out of bed because of complication, as soon as the patients' condition improved and they were medically allowed. Although "telling patients of the necessity of getting out of bed early" was associated with a lower incidence of complications, "pain control" was not associated with a lower incidence of complications. The pain level was higher for patients for whom nursing care for getting out of bed was recorded. In this hospital, pain medication was not used regularly but was used when required. Only approximately $22 \%$ of patients were provided pain medication before getting out of bed. Therefore, pain may not have been adequately controlled. In addition, although nursing care for getting out of bed did not directly predict lower mortality, the incidence of complications was a significant predictor of mortality. Therefore, nursing care for preventing complications is imperative.

In this study, the initial date for partial weight bearing was as early as it was in US hospitals, based on a previous study [12]. However, nursing care for weight bearing was not implemented with as many patients as was nursing care for getting out of bed. Walking exercises that included weight bearing are usually introduced by physical therapists in the rehabilitation room, and nurses may not necessarily be engaged in the walking exercises in the orthopedic ward in Japan. The majority of patients were discharged to other rehabilitation hospitals. The rehabilitation after discharge from the study hospital should have contributed towards the ambulatory ability at 3 months. However, this study revealed that nursing care for encouraging weight bearing in an acute care hospital was associated with not only ambulatory ability at discharge but also ambulatory ability at 3 months after surgery. This study indicated that nursing care soon after surgery in an acute care hospital can improve the long-term outcome of patients after hip fracture surgery.

Patients in Japanese acute care hospitals usually engage in physical therapy for only 20 minutes a day. Nursing care for encouraging weight bearing in daily living during the patient's stay in an orthopedic ward, such as when going to the bathroom or shops, is as important as or even more important than short periods of physical therapy in the rehabilitation room. While pain control for weight bearing was not associated with increased ambulatory ability, higher pain levels during initial weight bearing were associated with lower ambulatory ability at discharge. Fewer than $40 \%$ of the patients were provided with pain medication before weight bearing. Thus, pain was not effectively controlled at the time of weight bearing, nor was it controlled when getting out of bed. Feldt and Oh [13] also reported that undertreated postoperative pain contributes to poor functional outcomes for surgical hip fracture patients. Zabari et al. [14] reported that the proactive monitoring of pain in surgical hip fracture patients was associated with a better rehabilitation outcome as assessed by functional independence measures. Pain control is critical for weight bearing after surgery. Because the introduction of DPC reduced ambulatory ability at discharge even though LOS increased, it is necessary to improve ambulatory ability through nursing care.

Nursing care does not directly predict a shorter LOS after surgery, but the incidence of complications was associated with longer LOS after surgery. Patients could be discharged earlier if their ambulatory ability improved earlier. Arinzon et al. reported that after hip fracture surgery, the frequency of having elderly patients with a higher pain level on admission was associated with a longer stay at the rehabilitation hospital [15]. Therefore, nursing care aimed at preventing complications and encouraging weight bearing with controlled pain would subsequently contribute to shorter LOSs. Physical therapists and nurses should more willingly engage in rehabilitation in orthopedic wards.

\section{Limitations and Future Research}

This study collected data from only one hospital in Japan; therefore, the generalizability is limited. The national average LOS for musculoskeletal diseases, including hip fractures, in 2008 was 36.0 days [16]. The LOS of DPC hospitals is usually shorter than average, and the study hospital had an even shorter LOS than average before introducing DPC. This can be the reason that LOS was prolonged after DPC was introduced. This study collected data retrospectively from medical records. The actual nursing care may not have been accurately recorded. Patient outcome after discharge was collected from a survey that relied on patient/family reporting and, therefore, may not necessarily be accurate.

An early ambulation with full weight bearing as tolerated is the basic comprehensive care or older hip fracture surgery patients [17]. Further research is necessary to improve the quality of nursing care for early ambulation and prevention of complications. It is necessary to make a protocol for controlling pain and for encouraging weight bearing under controlled pain in daily living in the orthopedic ward so that patients' ambulatory ability will improve quickly.

Furthermore, the effect of the protocol should be evaluated in the future.

\section{Conclusion}

Nursing care for encouraging patients to get out of bed was associated with a lower incidence of complications. The incidence of complications was associated with a longer LOS after surgery and mortality. Nursing care for encouraging weight bearing was associated with increased ambulatory ability not only at discharge but also 3 months after surgery. Pain was not adequately controlled, and higher pain levels predicted a reduced ambulatory ability at discharge. Pain control is critical for weight bearing. Nursing care that prevents complications and encourages weight bearing under controlled pain 
Citation: Kondo A, Sada K, Yamaguchi C, Fujimoto E (2012) Nursing Care after Hip Fracture Surgery Predicts Patient Ambulatory Ability at 3 Months after Surgery. J Nurs Care S5:002. doi:10.4172/2167-1168.S5-002

Page 7 of 7

is important for better hip fracture patient outcomes. In addition to physical therapists, nurses should also be more willingly engaged in rehabilitation in orthopedic wards.

\section{Acknowledgment}

This work was supported by JSPS KAKENHI Grant Number 22592424, The Health Care Science Institute, and Foundation for Health Facilities Development.

\section{References}

1. Tsuboi M, Hasegawa Y, Suzuki S, Wingstrand H, Thorngren KG (2007) Mortality and mobility after hip fracture in Japan: a ten-year follow-up. J Bone Joint Surg $\mathrm{Br}$ 89: 461-466.

2. Robbins JA, Biggs ML, Cauley J (2006) Adjusted mortality after hip fracture: From the cardiovascular health study. J Am Geriatr Soc 54: 1885-1891.

3. Fitzgerald JF, Moore PS, Dittus RS (1988) The care of elderly patients with hip fracture. Changes since implementation of the prospective payment system. N Engl J Med 319: 1392-1397.

4. Kondo A, Kawabuchi K (2012) Evaluation of the introduction of a diagnosis procedure combination system for patient outcome and hospitalisation charges for patients with hip fracture or lung cancer in Japan. Health Policy 107: 184193.

5. Ministry of Health Labour and Welfare 2010 Health Statistics (2012) Life Tables.

6. (2003) The effects of introducing critical pathways for hip fracture patients: a multisite study in Japan. Nihon Iryou Management Gakkai Zasshi (The Journal of Japan Society for Health Care Management) 4: 395-400.

7. Kondo A, Zierler BK, Isokawa $\mathrm{Y}$, Hagino H, Ito $\mathrm{Y}$, et al. (2010) Comparison of lengths of hospital stay after surgery and mortality in elderly hip fracture patients between Japan and the United States - the relationship between the lengths of hospital stay after surgery and mortality. Disabil Rehabil 32: 826-835.

8. Halbert J, Crotty M, Whitehead C, Cameron I, Kurrle S, et al. (2007) Multidisciplinary rehabilitation after hip fracture is associated with improved outcome: A systematic review. J Rehabil Med 39: 507-512.

9. Gregersen M, Mørch MM, Hougaard K, Damsgaard EM (2012) Geriatric intervention in elderly patients with hip fracture in an orthopedic ward. J Inj Violence Res 4: 45-51.

10. Olsson LE, Hansson E, Ekman I, Karlsson J (2009) A cost-effectiveness study of a patient-centred integrated care pathway. J Adv Nurs 65: 1626-1635.

11. Siu AL, Penrod JD, Boockvar KS, Koval K, Strauss E, et al. (2006) Early ambulation after hip fracture: effects on function and mortality. Arch Intern Med 166: 766-771.

12. Kondo A, Hagino H, Zierler BK (2010) Determinants of ambulatory ability afte hip fracture surgery in Japan and the USA. Nurs Health Sci 12: 336-344

13. Feldt KS, Oh HL (2000) Pain and hip fracture outcomes for older adults. Orthop Nurs 19: 35-44

14. Zabari A, Lubart E, Ganz FD, LeibovitzA(2012) The effect of a pain managemen program on the rehabilitation of elderly patients following hip fracture surgery. Isr Med Assoc J 14: 104-106.

15. Arinzon Z, Gepstein R, Shabat S, Berner Y (2007) Pain perception during the rehabilitation phase following traumatic hip fracture in the elderly is an important prognostic factor and treatment tool. Disabil Rehabil 29: 651-658.

16. Ministry of Health Labour and Welfare 2008 Patients' data.

17. Pioli G, Davoli ML, Pellicciotti F, Pignedoli P, Ferrari A (2011) Comprehensive care. Eur J Phys Rehabil Med 47: 265-279. 